\title{
Congenital Disorders of Glycosylation (CDG): A Rapidly Expanding Group of Neurometabolic Disorders
}

\author{
Stephanie Grünewald, Gert Matthijs \\ Center for Human Genetics, Leuven/Belgium
}

The recently delineated Congenital Disorders of Glycosylation (CDG), formerly known as Carbohydrate-Deficient Glycoprotein syndromes, are a group of inherited multisystem diseases due to defective $\mathrm{N}$-glycosylation of proteins. Protein glycosylation is a frequent posttranslational modification and many secreted and membranous proteins have covalently bound carbohydrate units. These serve a variety of functions, allowing correct folding of the proteins, their protection against proteases and modulation of their biological activities [17]. The biosynthesis of N-linked oligosaccharides is elaborate and numerous glycosyltransferases are involved, attaching sugars to a growing lipid-linked oligosaccharide chain, stepwise. The donors are either nucleotide-activated or dolichol phosphatelinked sugars for these transfer reactions. Finally, the completed structure $\left(\mathrm{Gluc}_{3} \mathrm{Man}_{9} \mathrm{GlcNAc}_{2}\right.$ ) is transposed en bloc within the endoplasmatic reticulum (ER). It is then attached to an asparagine residue of a nascent protein via the oligosaccharyltransferase complex. In the Golgi compartment, several glycosidases can remodel the oligosaccharide chain into a more complex structure by removal of mannose residues and the addition of $\mathrm{N}$-acetylglucosamine, galactose, fucose and sialic acid residues [13].

Considering the ubiquitous presence of glycosylation and the multiple functions of the glycans, it is obvious that defects in the biosynthesis of $\mathrm{N}$-glycoproteins will be detrimental and result in a broad spectrum of clinical signs and symptoms. In 1980, Jaeken and colleagues described the first patients retrospectively diagnosed as CDG-Ia, with multisystem involvement including developmental delay, dysmorphic features and endocrine and biochemical abnormalities [7]. From the early 80s, isoelectric focussing (IEF) of serum transferrin has been a powerful tool to search for defects of N-glycosylation. When a protein is hypoglycosylated, the number of negatively charged sialic acids of serum transferrin is diminished, which results in a cathodal shift in IEF. This test, however, cannot distinguish between different types of CDG and additional studies must be performed to reach a definitive diagnosis. In the last few years, many new patients were identified with an abnormal transferrin pattern. Up to now six different defects were delineated. Much of the recent progress was achieved by tak-

Neuropediatrics 2000; 31: 57-59

(c) Georg Thieme Verlag Stuttgart · New York ISSN 0174-304X ing advantage of what is known in yeast: the early steps in Nglycosylation are highly conserved between eukaryotes, and yeast mutants have proven to be a powerful tool in the characterisation of novel types of CDG-I.

In contrast to other metabolic disorders, in which defects are restricted to one organelle, the enzyme defects in CDG are found in the cytosol, the ER and the Golgi compartment. The decreased activity of two cytosolic enzymes, phosphomannomutase 2 (in CDG-Ia) [14,16] and phosphomannose isomerase (in CDG-Ib) [9] result in a depletion of the GDP-mannose pool, required for the biosynthesis of the lipid-linked oligosaccharide chain (LLO). Deficiencies of the ER located $\alpha-1,3$ glycosyltransferase (in CDG-Ic) $[1,5,11]$ and the $\alpha-1,3$ mannosyltransferase (in CDG-Id) [12] impair the assembly of the LLO. Mutations in a gene coding for a subunit of the dolichol-phosphate mannose synthase (in CDG-Ie) $[6,10]$ result in a shortage of the donor molecule phosphate mannose.

The new classification (Table $\mathbf{1}$ ) follows the recommendations of a group of experts in the field at the "First International Workshop on CDGS" (November 1999 in Leuven, Belgium). This nomenclature no longer primarily refers to the transferrin pattern in IEF, but rather divides CDG in two groups, on the basis of the localisation of the enzymatic defect in the biosynthetic pathway of N-glycans. Disorders which affect the assembly of the dolichylpyrophosphate-linked oligosaccharide and/or its transfer to the asparagine residues on the nascent polypeptide are classified as CDG-I. CDG-II comprises the defects in the subsequent processing of the protein-bound glycans. The latter group includes CDG-IIa which results from a reduced $\mathrm{N}$-acetylglucosaminyltransferase II activity [15].

Although all disorders grouped as CDG-I result from a defective assembly or transport of the LLO, the corresponding patients display distinctive symptoms. Most patients with CDGI present with mild to severe neurologic dysfunction and developmental delay. CDG-Ia represent the majority of cases, and patients classically show dysmorphic features, moderate to severe psychomotor retardation and a variable non-neurological involvement with inverted nipples, abnormal fat distri-

Received and Accepted after Revision: March 31, 2000 
Table 1 New classification of Congenital Disorders of Glycosylation

\begin{tabular}{|c|c|c|c|c|}
\hline Type & Old synonym & $\begin{array}{l}\text { Defect and localization } \\
\text { (cytoplasmatic, Endoplasmatic Reticulum, Golgi Apparatus) }\end{array}$ & $\begin{array}{l}\text { Defective } \\
\text { gene }\end{array}$ & $\begin{array}{l}\text { Updated } \\
\text { synonym }\end{array}$ \\
\hline \multirow[t]{6}{*}{ Type I } & & $\begin{array}{l}\text { Defects in the synthesis of the dolichol-pyrophosphate-linked } \\
\text { oligosaccharide chain and/or its transfer onto the protein }\end{array}$ & & CDG-I \\
\hline & Type la & Phosphomannomutase (c) & PMM2 & CDG-la \\
\hline & Type Ib & Phosphomannose Isomerase (c) & PMI & CDG-Ib \\
\hline & Type Ic/V $\alpha-1,3$ & Glucosyltransferase (ER) & ALG6 & CDG-IC \\
\hline & Type IV $\alpha-1,3$ & Mannosyltransferase (ER) & ALG3 & CDG-Id \\
\hline & & Dolichol-P-Man Synthase 1 (ER) & DPM 1 & CDG-le \\
\hline \multirow[t]{2}{*}{ Type II } & & Defects in the modifications of the protein-bound oligosaccharide chains & & CDG-II \\
\hline & Type II & N-Acetyl-Glucosaminyltransferase II (GA) & MGAT2 & CDG-Ila \\
\hline Type $x$ & & All defects in the synthesis of $\mathrm{N}$-glycoproteins, incompletely characterized & & CDG-x \\
\hline
\end{tabular}

$\mathrm{c}=\mathrm{cytosol}, \mathrm{ER}=$ endoplasmatic reticulum, $\mathrm{GA}=$ Golgi apparatus

bution and cerebellar hypoplasia [8]. The latter triad has been the hallmark of CDG. However, a few patients known to have CDG-Id and CDGT-Ie lack this triad and still have a severe form of the disease. In contrast, CDG-Ib patients present with almost exclusively hepato-intestinal symptoms. CDG-Ic is different again. In this issue of Neuropediatrics, Hanefeld and colleagues point out that the clinical presentation in a young girl closely resembles a mild form of CDG-Ia. Abnormal results for clotting factors, low values for thyroxin in addition to unusual clinical features, prompted the authors to perform the IEF of serum transferrin. LLO-analyses of patient's fibroblasts revealed an accumulation of $\mathrm{Man}_{9} \mathrm{GlcNAc}_{2}$ structures and metabolic studies documented an $\alpha-1,3$ glucosyltransferase deficiency [11]. The molecular studies now show that the patient is homozygous for an in-frame deletion at position 299 , confirming the diagnosis of CDG-Ic.

There is a striking similarity of the clinical picture of the present case with that of 8 other CDG-Ic patients, who were all homozygous for an A333 V mutation [4]. However, a slow progressive cerebellar atrophy of postnatal onset has not been observed before in CDG-Ic. It demonstrates the variable clinical course in CDG-Ic, probably due to different mutations in the disease gene. This report illustrates again the broad clinical spectrum of CDG and it is unlikely that the full clinical spectrum of these disorders has been delineated yet. CDG should be suspected: 1. in patients presenting with the cardinal symptoms of CDG-Ia and CDG-Ib (inverted nipples, abnormal fat distribution, cerebellar hypoplasia or protein-loosing enteropathy) and 2. in children with a combination of symptoms frequently associated with CDG (failure to thrive, muscular hypotonia, mental retardation, epilepsy, retinitis pigmentosa and/ or abnormalities in laboratory results of glycoproteins). So far the IEF of serum transferrin has been used to identify N-glycosylation defects with glycoprotein abnormalities of serum proteins. Recently, the first indication that defects in the biosynthesis of $\mathrm{N}$-glycoproteins may be limited to the central nervous system was found in the study on $\beta$-trace protein, a N-glycoprotein synthesised in brain [3]. Not only will these and further investigations give us some insights into the pathogenic role of hypoglycosylation in brain, they also indicate that other diagnostic tools will be necessary.
These are exciting times for people involved in CDG. Within months, CDG-Ic, CDG-Id and CDG-Ie were added to the list of known disorders. In the near future, it seems certain that more disorders will emerge, in particular in CDG-II. The complexity of CDG-II will exceed that of CDG-I because of the complexity of the processing of the $\mathrm{N}$ - and O-glycan in the Golgi. Camillo Golgi (1843-1926) initiated basic research work on this tangled compartment. He was awarded the Nobel Prize in 1906 for his silver osmium staining technique (the "reazione nera") [2]. 25 years had been necessary to discover the "apparato reticolare interno". Now, a hundred years later, we are still far away from fully understanding this complex compartment, but progress in CDG research might give some more light and insight to these most interesting structures.

\section{References}

${ }^{1}$ Burda P, Borsig L, de Rijk-van Andel J, Wevers R, Jaeken J, Carchon $\mathrm{H}$ et al. A novel carbohydrate-deficient glycoprotein syndrome characterized by a deficiency in glycosylation of the dolichollinked oligosaccharide. J Clin Invest 1998; 102: 647-652

2 Dröscher A. Camillo Golgi and the discovery of the Golgi apparatus. Histochem Cell Biol 1998; 109: 425-430

${ }^{3}$ Grünewald S, Huyben K, de Jong JGN, Smeitink JAM, Rubio E, Boers GHJ et al. $\beta$-Trace protein in human cerebrospinal fluid: a diagnostic marker for N-glycosylation defects in brain. Biochim Biophys Acta 1999; 1455: 54-60

${ }^{4}$ Grünewald S, Imbach T, Hujben H, Rubio-Gozalbo ME, Verrips A, de Klerk JBC et al. Clinical and biochemical characteristics of Congenital Disorder of Glycosylation: CDG-Ic, the first recognized human ER defect in N-glycan synthesis. Ann Neurol (in press)

${ }^{5}$ Imbach T, Burda P, Kuhnert P, Wevers R, Aebi M, Berger EG et al. A mutation in the human ortholog of the Saccharomyces cerevisiae ALG6 gene causes carbohydrate-deficient glycoprotein syndrome type-Ic. Proc Natl Acad Sci USA 1999; 96: 6982 - 6987

${ }^{6}$ Imbach T, Schenk B, Schollen E, Burda P, Stutz A, Grünewald S et al. Deficiency of dolichol-phosphate-mannose synthase 1 causes congenital disorder of glycosylation type Ie. J Clin Invest 2000; 105, 2: $233-239$

${ }^{7}$ Jaeken J, Vanderschueren-Lodeweyckx M, Casaer P, Snoeck L, Corbeel L, Eggermont E et al. Familial psychomotor retardation with markedly fluctuating serum prolactin, FSH and GH levels, partial TBG-deficiency, increased serum arylsulfatase $A$ and increased CSF protein: a new syndrome? Pediatr Res 1980; 14: 179 
${ }^{8}$ Jaeken J, Casaer P. Carbohydrate-deficient glycoconjugate (CDG) syndromes: a new chapter of neuropaediatrics. Eur J Paed Neurol 1997; 2/3: $61-66$

${ }^{9}$ Jaeken J, Matthijs G, Saudubray JM, Dionisi-Vici C, Bertini E, de Lonlay P et al. Phosphomannose-isomerase deficiency: A carbohydrate-deficient glycoprotein syndrome with hepatic-intestinal presentation. Am J Hum Genet 1998; 62: 1535-1539

$10 \mathrm{Kim}$ S, Westphal V, Srikrishna G, Metha DP, Peterson S, Filiano J et al. Dolichol phosphate mannose synthase (DPM1) define congenital disorder of glycosylation Ie (CDG-Ie). J Clin Invest 2000; 105,2: $191-198$

${ }^{11}$ Körner C, Knauer R, Holzbach U, Hanefeld F, Lehle L, von Figura K. Carbohydrate-deficient glycoprotein syndrome type V: Deficiency of dolichol-P-Glc:Man $\mathrm{GlcNAc}_{2}$-PP-dolichol glucosyltransferase. Proc Natl Acad Sci USA 1998; 95: 13200-13205

${ }^{12}$ Körner C, Knauer R, Stephani U, Marquardt T, Lehle L, von Figura K. Carbohydrate-deficient glycoprotein syndrome type IV: deficiency of dolichol-P-Man: $\mathrm{Man}_{5} \mathrm{GlcNAc}_{2}$-PP-dolichyl mannosyltransferase. EMBO J 2000; 18: 6816-6822

${ }^{13}$ Kornfeld R, Kornfeld S. Assembly of asparagine-linked oligosaccharides. Anu Rev Biochem 1985; 54: 631 - 664

14 Matthijs G, Schollen E, Pardon E, Veigha-Da-Cunha M, Jaeken J, Cassiman JJ et al. Mutations in PMM2, a phosphomannomutasedeficient glycoprotein type I syndrome (Jaeken syndrome). Nat Genet 1997; 16: 88-92

${ }^{15}$ Tan J, Dunn K, Jaeken J, Schachter H. Mutations in the MGAT2 gene controlling complex $\mathrm{N}$-glycan synthesis cause carbohydrate deficient glycoprotein syndrome type II, an autosomal recessive disease with defective brain development. Am J Hum Genet 1996; 59: 810-817

${ }^{16}$ Van Schaftingen E, Jaeken J. Phosphomannomutase deficiency is a cause of carbohydrate deficient glycoprotein syndrome type I. FEBS Lett 1995; 377: $318-320$

${ }^{17}$ Varki A. Biological roles of oligosaccharides: all theories are correct. Glycobiology 1993; 3: $97-130$
Stephanie Grünewald and Gert Matthijs

Center for Human Genetics

U. Z. Gasthuisberg

Herestraat 49

3000 Leuven

Belgium

E-mail: stephanie.gruenewald@med.kuleuven.ac.be 